\title{
Indicadores da Qualidade do Substrato para Monitoramento de Áreas de Mineração Revegetadas
}

\author{
Raquel Olimpia Peláez Ocampo Almeida ${ }^{1}$, Luis Enrique Sánchez ${ }^{1}$ \\ ${ }^{1}$ Departamento de Engenharia de Minas e de Petróleo, Universidade de São Paulo - USP, São Paulo/SP, Brasil
}

\begin{abstract}
RESUMO
Um procedimento para monitoramento e obtenção de indicadores para avaliação da recuperação ambiental de áreas mineradas foi desenvolvido e testado. Quatro bacias de disposição de rejeitos de mineração de areia industrial revegetadas em épocas distintas constituíram uma cronossequência de 14 anos que possibilitou a observação das mudanças das características físicas e químicas do substrato e o estabelecimento de relações com parâmetros de crescimento da vegetação. Uma análise de covariâncias multivariada entre os indicadores identificou a densidade de solo, teores de matéria orgânica e fósforo e $\mathrm{pH}$ como os mais apropriados para avaliar a qualidade do substrato e para atuarem como indicadores de resultados de ações de recuperação das bacias estudadas. Esse procedimento mostrou-se um instrumento de fácil aplicação para o acompanhamento da evolução da recuperação ambiental e para a obtenção de parâmetros quantitativos que facilitem a avaliação dos resultados das ações de recuperação.
\end{abstract}

Palavras-chave: bacias de rejeito, revegetação, monitoramento.

\section{Substratum Quality Indicators for Monitoring Revegetated Mining Areas}

\begin{abstract}
Indicators of substratum quality for monitoring the state of rehabilitation in mining areas were selected on the basis of a study conducted in an operating industrial sand mine. Four study plots were established in decommissioned tailing ponds restored with native plant species for the past 14 years, allowing for $10+$ years of simulated monitoring. Substratum samples were collected to measure several physical and chemical properties, while plant development was assessed using conventional parameters. A multivariate covariance analysis led to the selection of soil density, contents of organic matter and phosphorous, as well as soil $\mathrm{pH}$, as suitable variables with ample possibilities to be used as indicators for the conditions studied. Measuring these parameters is a practical, affordable, easy-to-use tool to monitor the evolution of environmental rehabilitation and obtain quantitative parameters that allow for an objective assessment of the results.
\end{abstract}

Keywords: tailings ponds, revegetation, monitoring. 


\section{INTRODUÇÃO}

O restabelecimento de comunidades vegetais nativas é uma das formas mais utilizadas para recuperar áreas degradadas pela mineração, criando um novo uso do solo que visa à conservação ambiental. $\mathrm{O}$ processo de restabelecimento pode ser longo, o que determina a necessidade de aferir os resultados desde os primeiros anos após a implementação das medidas de recuperação. Mediante monitoramento apropriado, é possível verificar se os objetivos pretendidos estão sendo alcançados e determinar a partir de quando esses resultados podem ser considerados satisfatórios. Só então se poderá confirmar que a área atende a critérios preestabelecidos de recuperação ambiental.

A ferramenta-chave para esse controle é o monitoramento, entendido como o conjunto de ações ou procedimentos destinados a avaliar o avanço ou o sucesso da recuperação de uma área degradada. Mediante monitoramento, também é possível documentar e demonstrar os resultados dos programas de gestão ambiental, avaliar as práticas de manejo utilizadas e orientar ações corretivas (Neri \& Sánchez, 2010; Sánchez, 2010). Inúmeros indicadores de desempenho podem ser utilizados para a avaliação da recuperação ambiental em minas, embora os mais usuais estejam atualmente relacionados ao crescimento da vegetação. Em qualquer tipo de monitoramento adotado, o grande desafio é desenvolver ou adaptar procedimentos, métodos e critérios válidos para que forneçam, com exatidão, as informações desejadas a custos aceitáveis. Trabalhos como os de Bento (2009), Knapik \& Maranho (2007), Reis (2006) e Almeida \& Sánchez (2005) sugerem indicadores aplicáveis à avaliação de áreas de mineração revegetadas, enquanto Corrêa \& Bento (2010) propõem um índice de qualidade do substrato, destacando a importância de acompanhar sua qualidade física quando o objetivo é o restabelecimento de vegetação nativa.

No caso da avaliação da recuperação das bacias de disposição de rejeitos, o monitoramento do solo acondicionado (substrato) se faz indispensável devido à relação direta entre sua qualidade e o desenvolvimento da vegetação. Esse substrato resulta do processo de secagem do rejeito, que geralmente se apresenta como uma polpa aquosa, contendo predominantemente as frações granulométricas argila e silte, depositada em bacias de contenção. Após seu bombeamento para as bacias, o rejeito é recoberto por uma camada de material arenoso e uma camada de solo superficial, cuja espessura depende de sua disponibilidade em cada mina. Esse processo gera um substrato muito compacto e de baixos teores de nutrientes, situação que dificulta o desenvolvimento das plantas. Assim, são necessárias estratégias específicas para o sucesso da revegetação em tais áreas, de modo a criar condições edáficas mais favoráveis para o crescimento e sustentação das mudas plantadas (Corrêa \& Bento, 2010; Silva \& Corrêa, 2010). Por esse motivo é importante monitorar o estado do substrato como complemento da avaliação do estado da vegetação. As informações sobre a qualidade ambiental do local seriam então mais completas e forneceriam dados mais elucidativos sobre a eficácia dos procedimentos de recuperação aplicados e sua perspectiva de sustentabilidade no longo prazo.

O presente trabalho tem como objetivo propor e testar um método de monitoramento da recuperação de bacias de rejeitos revegetadas mediante o acompanhamento de características físicas e químicas do substrato, em paralelo ao acompanhamento do desenvolvimento da vegetação. A metodologia sugerida foi desenvolvida em um caso concreto, apresentando-se uma descrição detalhada das atividades e tarefas necessárias para sua melhor aplicação.

Uma vez que o substrato provê não somente o suporte físico para as plantas mas também nutrientes e o ambiente para a fauna do solo, e que suas características modificam-se ao longo do tempo como resultado das medidas de recuperação, é pertinente avaliar suas condições em paralelo à avaliação do desenvolvimento das plantas, de maneira que se possa associar ambas as evoluções.

\section{MATERIAL E MÉTODOS}

A pesquisa foi conduzida com base na observação e no acompanhamento da evolução das características físicas e químicas do substrato e da vegetação estabelecida. Os procedimentos e as atividades que compõem a metodologia estão divididos em:

- Estudo de documentos: Visa conhecer o histórico do local e as ações de manejo praticadas. Destacam-se o conhecimento do tipo de mineração praticado, os impactos ambientais decorrentes, a caracterização 
da degradação gerada e o histórico das atividades de recuperação efetuadas, com as metas estabelecidas e as datas de realização, entre outros aspectos. Fazem-se necessários também o estudo de plantas topográficas e desenhos da área da mina.

- Trabalhos de campo: Compreendem o reconhecimento do local em estudo, as amostragens do substrato e as observações da vegetação. É preciso familiarizar-se com os locais de estudo e com o seu entorno, visando estabelecer as melhores condições para a coleta das amostras do substrato e a captação dos dados da vegetação, tendo-se em conta que a amostragem deve ser representativa das condições de toda a área de estudo. Deve-se também estabelecer locais de referência que possibilitem comparações elucidativas e facilitem as avaliações.

- Determinações laboratoriais: Geram dados quantitativos dos indicadores de qualidade do substrato; propõese basicamente a determinação das variáveis físicas densidade de solo e porosidade total (método do cilindro volumétrico) e a realização de análise química do solo para determinação de $\mathrm{pH}$ (método $\mathrm{CaCl}_{2} 0,01$ mol. $\mathrm{L}^{-1}$ ), carbono orgânico (método colorimétrico), fósforo, potássio, cálcio e magnésio (método resina trocadora de íons), acidez potencial (método $\mathrm{pH}$ SMP), capacidade de troca catiônica, soma de bases e porcentagem de saturação de bases.

- Análise e interpretação dos resultados: Os dados obtidos com a mensuração periódica dos atributos permitem comparar os resultados no decorrer do tempo. Valores de referência para cada parâmetro, obtidos no próprio estudo ou preestabelecidos com base na literatura, podem auxiliar no diagnóstico. Esse exercício deverá ser realizado também com os parâmetros descritivos da vegetação, visando estabelecer uma relação com os dados do substrato. Dessa forma é possível avaliar a evolução do conjunto (substrato e plantas) e os fatores determinantes no desenvolvimento da vegetação. Os parâmetros do substrato identificados como mais adequados no fornecimento das informações sobre o estado da revegetação e a sua evolução, vinculados às ações realizadas, serão então selecionados como indicadores efetivos de desempenho dos programas de revegetação.

\subsection{Estudo de caso}

Para verificar a aplicabilidade da metodologia proposta foi observada uma cronossequência de revegetação em uma mina. A existência de áreas onde o plantio foi realizado em diferentes épocas segundo o mesmo protocolo permite simular um seguimento da evolução da qualidade do substrato e do desenvolvimento da vegetação por um período de 14 anos.

\subsection{1. Área de estudo}

O estudo foi realizado na Mineração Descalvado, que extrai areia industrial a céu aberto e se situa no município de Descalvado, SP, nas coordenadas centrais UTM 7.570,206 km N e 229,241 km E. O clima da região, segundo a classificação de Köppen, é do tipo Cwa, com estação seca no inverno e chuvas abundantes e intensas no verão. A precipitação anual média é de $1.700 \mathrm{~mm}$ e a temperatura média de $24 \mathrm{oC}$, a umidade relativa do ar varia de $20 \%$ a $30 \%$ (Sentelhas et al., 1999). No entorno da mina, a cobertura vegetal compreende áreas com vegetação nativa (Cerradão), áreas revegetadas e pastagens. Ab'Sáber (2009) menciona que a maioria das espécies de ocorrência nos Cerradões também ocorrem no Cerrado sentido restrito, contudo são mais desenvolvidas, possuem maior biomassa vegetal e incluem sub-bosques e alguma vegetação herbácea. Predominam os solos ácidos, de baixo teor de nutrientes e com baixa atividade coloidal.

O local da pesquisa é uma antiga bacia de rejeito com 5 ha onde, a partir de 1995, foram sendo plantadas espécies arbóreas nativas como parte do processo de recuperação. A área denominada A1 foi revegetada em 1995, completando, na época da pesquisa de campo, 14 anos de revegetação; a área A2 foi revegetada em 1998 (11 anos); a área A3 foi revegetada em 2001 (8 anos); e a área A4 foi revegetada em 2003 (6 anos). Tais áreas são contíguas e configuram a cronossequência utilizada para a observação da evolução temporal do substrato e da vegetação. A mata nativa do entorno (A5) é a área de referência. Uma bacia de rejeito ainda sem plantio (identificada como A6), mas com características similares às áreas em estudo, foi escolhida para constituir o ano zero da cronossequência.

$\mathrm{Na}$ mina, o beneficiamento da areia consiste na separação granulométrica e remoção do óxido de ferro. O processo emprega métodos físicos e é realizado por via úmida, gerando rejeitos silte-argilosos depositados em bacias localizadas dentro da própria cava, aproveitando os espaços já minerados. A recuperação da antiga bacia iniciou-se com a secagem e o adensamento dos rejeitos dispostos, seguida da colocação de uma camada de material estéril arenoso e, finalmente, de uma camada de solo superficial. A adição desses materiais é uma medida para o melhoramento das condições edáficas 
da bacia, atenuando o efeito negativo do material fino do rejeito no crescimento das plantas. Processo similar de preparação do substrato foi constatado por Costa \& Zocche (2009) numa área de mineração de carvão em recuperação no sul de Santa Catarina, mas nesse caso os autores o denominaram construção de solos. $\mathrm{Na}$ superfície da bacia foi adicionada $1 \mathrm{Mg} \mathrm{ha}^{-1}$ de calcário e realizou-se semeadura de capim braquiária (Brachiaria decumbens) para facilitar a consolidação do substrato. Posteriormente houve plantio de mudas de espécies arbóreas e nas covas, preenchidas com solo superficial, foi adicionada uma mistura de $200 \mathrm{~g}$ de calcário, $15 \mathrm{~L}$ de esterco e $300 \mathrm{~g}$ de fertilizante fosfatado. Os cuidados pós-plantio foram replantio, adubação, irrigação, roça e combate de pragas e doenças até que as mudas atingissem 2 a $3 \mathrm{~m}$ de altura. Análises anuais de solo, realizadas no substrato, foram utilizadas para avaliação da correção da acidez e da adubação.

\subsubsection{Amostragem do substrato}

A amostragem foi realizada em três trincheiras (repetições) em cada uma das seis áreas citadas (A1, A2, A3, A4, A5 e A6). Houve extração de uma amostra a cada $20 \mathrm{~cm}$, desde a superfície até $80 \mathrm{~cm}$ de profundidade (cinco amostras por trincheira e 15 amostras por área), totalizando 90 amostras. Foram coletados três tipos de amostras: (1) amostra indeformada para análise de densidade de solo (método do cilindro volumétrico); (2) amostra de $500 \mathrm{~g}$ destinada à análise granulométrica; e (3) amostra de $500 \mathrm{~g}$ destinada às análises químicas. A escolha das profundidades de amostragem foi orientada pela observação do perfil do solo em trincheiras de exploração para se observar o crescimento das raízes. As trincheiras mostraram que o maior desenvolvimento das raízes se dava nos primeiros $20 \mathrm{~cm}$, mas o crescimento chegava até $60-70$ $\mathrm{cm}$ de profundidade. Uma vez definida a espessura da primeira camada como $20 \mathrm{~cm}$, as demais foram estipuladas como de espessura igual.

\subsubsection{Observações da vegetação}

Para a obtenção das informações da vegetação (circunferência à altura do peito - CAP e altura de planta), em cada uma das áreas citadas foram selecionadas, ao acaso, cinco parcelas de $300 \mathrm{~m}^{2}$. O critério de inclusão estabeleceu todos os indivíduos arbóreos que apresentassem CAP igual ou maior a 5 $\mathrm{cm}$. Também foi realizada a identificação das espécies arbóreas e das mudas com regeneração espontânea. Para cada área, foi calculado o índice de diversidade de Shannon-Weaver (H’) (Coelho, 2000). Esse índice quantifica a diversidade de espécies arbóreas, considerando o mesmo peso entre as mais frequentes e as mais raras. Quanto maior o valor de $\mathrm{H}$, maior a diversidade florística da população em estudo. A estimativa de H’ é dada pela Fórmula 1:

$H^{\prime}=\frac{N \ln (N)-\sum_{i=1}^{s} n_{i} \ln \left(n_{i}\right)}{N}$

em que: $\mathrm{H}^{\prime}=$ índice de Shannon-Weaver; $\mathrm{n}_{\mathrm{i}}=$ número de indivíduos amostrados da i-ésima espécie; $\mathrm{N}$ = número total de indivíduos amostrados; $\mathrm{S}=$ número total de espécies amostradas; $\ln =$ logaritmo de base neperiana.

\subsubsection{Análise dos resultados obtidos}

Os resultados médios foram utilizados nas comparações entre as áreas de amostragem mediante a construção de intervalos de confiança de Bomferroni. Também foi testada a existência de correlação entre os atributos do substrato estudados, por meio do coeficiente de correlação de Pearson. Para compreender como as mudanças do substrato se interligam com a evolução da vegetação, as variáveis físicas e químicas do substrato foram estatisticamente relacionadas com as características da vegetação utilizando-se o modelo de análise de covariâncias multivariado (Tanaka et al., 2009), um modelo misto que permite verificar quais variáveis influenciam de forma significativa o desenvolvimento da vegetação.

\section{RESULTADOS E DISCUSSÃO}

Os resultados das análises físicas são apresentados na Tabela 1. Em todas as situações estudadas, ou seja, tanto nas diferentes áreas como nas diferentes profundidades observadas, a classe textural do substrato é predominantemente arenosa (Troeh \& Thompson, 2007). Esse parâmetro, assim como a densidade de partículas, não se constitui como indicador de mudanças em nenhuma das situações estudadas, mas ambos são importantes para a caracterização do substrato e seu posterior manejo. Quanto à densidade de solo (Ds), em geral os valores são altos nas áreas revegetadas (inclusive na superfície). Brady \& Weil (2007) fornecem valores habituais de Ds ao redor de 1,25 Mg.m ${ }^{-3}$ para solos de textura arenosa. Com o aumento 
Tabela 1. Resultados médios das variáveis físicas nas áreas de estudo.

Table 1. Average values of physical variables in the study areas.

\begin{tabular}{|c|c|c|c|c|c|c|c|}
\hline Áreas & $\begin{array}{l}\text { Profundidade } \\
\mathrm{cm}\end{array}$ & $\begin{array}{c}\text { Ds } \\
\mathrm{Mg} \cdot \mathrm{m}^{-3}\end{array}$ & $\begin{array}{c}\text { Dp } \\
M g \cdot \mathbf{m}^{-3}\end{array}$ & Porosidade & Argila & $\begin{array}{c}\text { Silte } \\
\% \%\end{array}$ & Areia \\
\hline \multirow{5}{*}{$\begin{array}{c}\text { A1 } \\
\text { (14 anos) }\end{array}$} & $0-20$ & 1,42 & 2,55 & 44,2 & 8,8 & 2,85 & 88,4 \\
\hline & $20-40$ & 1,49 & 2,45 & 41,5 & 9,5 & 1,1 & 89,6 \\
\hline & $40-60$ & 1,50 & 2,45 & 41,0 & 8,2 & 1,5 & 90,0 \\
\hline & $60-80$ & 1,45 & 2,55 & 42,9 & 9,8 & 1,7 & 88,6 \\
\hline & $80-100$ & 1,48 & 2,45 & 41,8 & 9,8 & 1,6 & 88,7 \\
\hline \multirow{5}{*}{$\begin{array}{c}\text { A2 } \\
\text { (11 anos) }\end{array}$} & $0-20$ & 1,55 & 2,6 & 41,2 & 5,6 & 4,5 & 89,9 \\
\hline & $20-40$ & 1,62 & 2,6 & 38,5 & 5,4 & 4,3 & 90,2 \\
\hline & $40-60$ & 1,63 & 2,7 & 38,0 & 6,4 & 2,9 & 90,7 \\
\hline & $60-80$ & 1,75 & 2,7 & 33,7 & 1,5 & 1,7 & 96,8 \\
\hline & $80-100$ & 1,79 & 2,7 & 32,1 & 4,8 & 3,7 & 91,5 \\
\hline \multirow{5}{*}{$\begin{array}{c}\text { A3 } \\
(8 \text { anos })\end{array}$} & $0-20$ & 1,42 & 2,6 & 46,0 & 4,6 & 4,8 & 90,6 \\
\hline & $20-40$ & 1,43 & 2,6 & 45,6 & 5,9 & 3,8 & 90,4 \\
\hline & $40-60$ & 1,56 & 2,6 & 40,6 & 6,6 & 3,6 & 89,9 \\
\hline & $60-80$ & 1,58 & 2,7 & 40,0 & 5,4 & 5,7 & 88,9 \\
\hline & $80-100$ & 1,75 & 2,7 & 33,5 & 8,1 & 1,1 & 90,8 \\
\hline \multirow{5}{*}{$\begin{array}{c}\text { A4 } \\
\text { (6 anos) }\end{array}$} & $0-20$ & 1,47 & 2,6 & 44,1 & 3,4 & 3,4 & 93,2 \\
\hline & $20-40$ & 1,70 & 2,6 & 35,6 & 6,2 & 2,7 & 91,1 \\
\hline & $40-60$ & 1,67 & 2,6 & 36,7 & 6,6 & 3,0 & 90,4 \\
\hline & $60-80$ & 1,71 & 2,6 & 35,0 & 8,4 & 4,3 & 87,2 \\
\hline & $80-100$ & 1,71 & 2,7 & 34,9 & 8,3 & 3,1 & 88,6 \\
\hline \multirow{5}{*}{$\begin{array}{c}\text { A5 } \\
\text { (mata nativa) }\end{array}$} & $0-20$ & 1,14 & 2,6 & 56,9 & 5,5 & 2,7 & 91,8 \\
\hline & $20-40$ & 1,44 & 2,6 & 45,2 & 3,6 & 4,3 & 92,1 \\
\hline & $40-60$ & 1,44 & 2,6 & 45,3 & 7,7 & 4,7 & 87,6 \\
\hline & $60-80$ & 1,44 & 2,6 & 45,3 & 9,7 & 5,3 & 85,1 \\
\hline & $80-100$ & 1,44 & 2,6 & 45,3 & 8,7 & 2,6 & 88,7 \\
\hline \multirow{5}{*}{ A6 (sem vegetação) } & $0-20$ & $1,14^{*}$ & 2,6 & & 4,2 & 3,0 & 92,8 \\
\hline & $20-40$ & & 2,6 & & 2,0 & 4,4 & 93,7 \\
\hline & $40-60$ & & 2,6 & & 3,6 & 5,2 & 91,2 \\
\hline & $60-80$ & & 2,6 & & 5,1 & 4,6 & 90,2 \\
\hline & $80-100$ & & 2,6 & & 5,0 & 4,5 & 90,5 \\
\hline
\end{tabular}

Ds: densidade de solo; Dp: densidade de partícula; ${ }^{\star}$ valor assumido da mata nativa.

da profundidade, os valores se tornaram mais altos, condição mais evidente na área A2 (11 anos). A Ds da área A6 (sem revegetação) não foi determinada, pois a área havia sido recém-aterrada com solo removido de área de mata nativa recentemente cortada, portanto, assumiu-se, para a camada superficial, o mesmo valor de Ds da mata nativa.

Os valores de Ds nas áreas revegetadas são superiores aos da área A5 de mata nativa. Esses valores elevados refletem a existência de compactação do substrato nessas áreas, considerando que a Ds é a medida quantitativa mais direta da compactação (Machado, 2003). Os procedimentos de secagem do rejeito, associado ao trânsito de caminhões e pás carregadoras para o preenchimento da bacia com o material estéril são identificados como causadores da compactação. Tal situação impede o maior aproveitamento de nutrientes e água pelas raízes, ao mesmo tempo em que a oxigenação torna-se deficiente. Uma constatação decorrente é que não foram observadas raízes crescendo a profundidades maiores que $60 \mathrm{~cm}$. Já na área $\mathrm{A} 5$, de mata nativa (sem compactação), as raízes crescem até mais de $1 \mathrm{~m}$ de profundidade. Outra observação importante é que a compactação não melhorou com o tempo no período observado. Seria esperado que, com maior tempo de revegetação, os valores de Ds diminuíssem até se aproximarem dos da mata nativa; contudo a área A2 (11 anos) apresenta os valores mais elevados de Ds, 
sendo que o tempo de revegetação é mais longo do que na área A3 (8 anos) e na área A4 (6 anos), sugerindo uma evolução negativa. Os resultados de porosidade confirmam maior quantidade de vazios no solo da área A5, de mata nativa, e a menor na área A2 (11 anos).

Assim como ocorreu nos resultados dos parâmetros físicos, os resultados dos parâmetros químicos (Tabela 2) tendem a apresentar valores mais altos próximo à superfície $(0-20 \mathrm{~cm})$. Da comparação entre as áreas em estudo, distingue-se que as intervenções de correção da acidez e adubação têm influenciado positivamente na situação nutricional das áreas revegetadas, apresentando, em muitos casos, valores mais favoráveis que os da área A5, de mata nativa. É o caso do teor médio de fósforo
$(\mathrm{P})$, cálcio $(\mathrm{Ca})$, potássio $(\mathrm{K})$, magnésio $(\mathrm{Mg})$ e soma de bases (SB). Esse fato denota uma melhoria nutricional considerável do substrato, o que tem favorecido o desenvolvimento da vegetação implantada. Esses resultados têm semelhança com os encontrados por Silva \& Corrêa (2010) no estudo da revegetação de uma cascalheira abandonada, também localizada em área de Cerrado. Como todas as áreas se apresentam muito ácidas, a correção melhorou o suprimento de cálcio e magnésio e favoreceu a disponibilidade de fósforo, sendo necessária prioritariamente para o desenvolvimento da vegetação na fase de mudas e geralmente recomendada nos planos de recuperação de áreas degradadas. O teor de matéria orgânica (MO) se apresenta alto em todas

Tabela 2. Resultados médios das variáveis químicas nas áreas de estudo.

Table 2. Average values of chemical variables in the study areas.

\begin{tabular}{|c|c|c|c|c|c|c|c|c|c|c|c|c|}
\hline & \multirow{2}{*}{$\begin{array}{l}\text { Profundidade } \\
\mathrm{cm}\end{array}$} & \multirow{2}{*}{$\underset{\mathrm{CaCl}_{2}}{\mathrm{pH}}$} & \multirow{2}{*}{$\begin{array}{c}\text { MO } \\
\mathrm{g} \mathrm{dm}^{-3}\end{array}$} & \multirow{2}{*}{$\begin{array}{c}\mathbf{P} \\
\mathrm{mg} \mathrm{dm}^{-3}\end{array}$} & $\mathrm{~K}$ & $\mathrm{Ca}$ & $\mathrm{Mg}$ & Al & $\mathrm{H}+\mathbf{A l}$ & SB & CTC & $\mathbf{V}$ \\
\hline & & & & & \multicolumn{7}{|c|}{ mmolc dm ${ }^{-3}$} & $\%$ \\
\hline \multirow{5}{*}{$\begin{array}{c}\text { A1 } \\
(14 \text { anos })\end{array}$} & $0-20$ & 3,8 & 23,0 & 8,0 & 0,7 & 6,0 & 6,0 & 8,7 & 57 & 10,0 & 66,7 & 16 \\
\hline & $20-40$ & 3,5 & 16,0 & 8,0 & 0,3 & 1,0 & 1,0 & 11,7 & 60 & 2,3 & 62,3 & 4 \\
\hline & $40-60$ & 3,5 & 16,0 & 6,0 & 0,3 & 1,3 & 1,3 & 11,3 & 54 & 2,6 & 56,9 & 5 \\
\hline & $60-80$ & 3,5 & 15,0 & 4,7 & 0,2 & 1,0 & 1,0 & 11,7 & 53 & 2,23 & 55,6 & 4 \\
\hline & $80-100$ & 3,5 & 17,0 & 5,0 & 0,2 & 1,0 & 1,0 & 12,3 & 53 & 2,2 & 55,5 & 4 \\
\hline \multirow{5}{*}{$\begin{array}{c}\text { A2 } \\
\text { (11 anos) }\end{array}$} & $0-20$ & 4,4 & 14,0 & 8,3 & 0,5 & 7,7 & 7,7 & 4,3 & 21 & 12,2 & 32,9 & 37 \\
\hline & $20-40$ & 3,9 & 9,0 & 1,0 & 0,1 & 1,7 & 1,7 & 8,7 & 22 & 2,8 & 25,1 & 11 \\
\hline & $40-60$ & 4,0 & 7,0 & 1,0 & 0,1 & 1,3 & 1,3 & 8,3 & 21 & 2,4 & 23,8 & 10 \\
\hline & $60-80$ & 4,9 & 6,0 & 1,3 & 0,1 & 3,3 & 3,3 & 1,0 & 11 & 5,1 & 16,1 & 32 \\
\hline & $80-100$ & 5,5 & 6,0 & 1,0 & 0,1 & 3,0 & 3,0 & 0,0 & 10 & 5,1 & 15,1 & 33 \\
\hline \multirow{5}{*}{$\begin{array}{c}\text { A3 } \\
\text { (8 anos) }\end{array}$} & $0-20$ & 3,9 & 27,0 & 10,0 & 0,6 & 7,3 & 7,3 & 8,7 & 56 & 12,6 & 68,9 & 20 \\
\hline & $20-40$ & 3,6 & 18,0 & 3,0 & 0,2 & 1,7 & 1,7 & 10,3 & 52 & 2,9 & 55,2 & 5 \\
\hline & $40-60$ & 3,7 & 15,0 & 2,0 & 0,2 & 1,3 & 1,3 & 11,0 & 46 & 2,5 & 48,5 & 7 \\
\hline & $60-80$ & 3,9 & 8,0 & 1,7 & 0,1 & 1,0 & 1,0 & 9,3 & 22 & 2,1 & 24,5 & 10 \\
\hline & $80-100$ & 4,0 & 6,0 & 1,0 & 0,1 & 1,3 & 1,3 & 7,0 & 15 & 2,4 & 17,8 & 14 \\
\hline \multirow{5}{*}{$\begin{array}{c}\text { A4 } \\
\text { (6 anos) }\end{array}$} & $0-20$ & 4,6 & 21,0 & 12,7 & 0,8 & 15,0 & 15 & 4,0 & 28 & 24,8 & 52,8 & 43 \\
\hline & $20-40$ & 4,0 & 10,0 & 1,3 & 0,1 & 2,3 & 2,3 & 9,3 & 23 & 3,8 & 27,1 & 15 \\
\hline & $40-60$ & 4,0 & 8,0 & 1,0 & 0,1 & 1,3 & 1,3 & 8,7 & 20 & 2,4 & 22,8 & 12 \\
\hline & $60-80$ & 4,0 & 9,0 & 1,3 & 0,1 & 1,3 & 1,3 & 8,0 & 22 & 2,4 & 24,8 & 12 \\
\hline & $80-100$ & 4,3 & 6,0 & 1,0 & 0,1 & 3,0 & 3,0 & 5,7 & 12 & 4,4 & 16,8 & 25 \\
\hline \multirow{5}{*}{$\begin{array}{c}\text { A5 } \\
\text { (mata nativa) }\end{array}$} & $0-20$ & 3,6 & 25,0 & 5,3 & 0,6 & 1,3 & 1,3 & 13,3 & 73 & 3,0 & 76,3 & 4 \\
\hline & $20-40$ & 3,8 & 13,0 & 1,7 & 0,2 & 1,0 & 1,0 & 10,3 & 34 & 2,2 & 36,6 & 6 \\
\hline & $40-60$ & 3,9 & 11,0 & 1,0 & 0,1 & 1,0 & 1,0 & 10,0 & 33 & 2,1 & 35,4 & 6 \\
\hline & $60-80$ & 3,8 & 9,0 & 1,0 & 0,1 & 1,7 & 1,7 & 10,0 & 34 & 2,8 & 36,8 & 8 \\
\hline & $80-100$ & 3,9 & 9,0 & 1,0 & 0,1 & 1,0 & 1,0 & 10,3 & 28 & 2,1 & 30,1 & 7 \\
\hline \multirow{5}{*}{$\begin{array}{c}\text { A6 } \\
\text { (sem vegeta- } \\
\text { ção) }\end{array}$} & $0-20$ & 4,0 & 7,0 & 1,0 & 0,1 & 1,0 & 1,0 & 7,0 & 20 & 2,1 & 21,8 & 10 \\
\hline & $20-40$ & 4,1 & 7,0 & 1,0 & 0,1 & 1,0 & 1,0 & 7,0 & 18 & 2,1 & 20,1 & 10 \\
\hline & $40-60$ & 4,1 & 7,0 & 1,0 & 0,1 & 1,7 & 1,7 & 6,3 & 17 & 3,1 & 20,5 & 15 \\
\hline & $60-80$ & 4,1 & 6,0 & 1,0 & 0,1 & 1,3 & 1,3 & 6,0 & 17 & 2,4 & 19,4 & 12 \\
\hline & $80-100$ & 4,2 & 6,0 & 1,0 & 0,1 & 3,3 & 3,3 & 6,3 & 16 & 5,1 & 21,5 & 23 \\
\hline
\end{tabular}

MO: teor de matéria orgânica; P: fósforo; K: potássio; Ca: cálcio; Al: alumínio; Mg: magnésio; CTC: capacidade de troca catiônica; V: porcentagem de saturação de bases; SB: soma de bases; $(\mathrm{H}+\mathrm{Al})$ : acidez potencial. 
as áreas estudadas, exceto em A6 (sem revegetação), particularmente na camada superficial, devido à queda de galhos e folhas da vegetação formada. Do mesmo modo, os baixos valores de SB observados na área A6, onde não houve calagem nem adubação, confirmam que os sítios de troca na CTC estão ocupados, na sua maioria, por cátions hidrogênio $\left(\mathrm{H}^{+1}\right)$ e alumínio $\left(\mathrm{Al}^{+3}\right)$, fato confirmado pela alta correlação $(0,97)$ encontrada entre $\mathrm{CTC}$ e acidez potencial $(\mathrm{H}+\mathrm{Al})$. Essas circunstâncias comprovam que o substrato das áreas de disposição de rejeitos é deficiente em nutrientes e altamente ácido, apontando a necessidade de correção de $\mathrm{pH}$ e adubação em trabalhos de revegetação. A mata nativa, embora também com solo de textura arenosa, apresenta valor de CTC elevado (maior que $50 \mathrm{mmolc}$. $\mathrm{dm}^{-3}$ ) na sua porção superficial, avaliando-se que há grande influência de $\mathrm{MO}$ no aporte de sítios de troca de cátions, considerando-se o baixo conteúdo de argila do solo e confirmada pela alta correlação encontrada entre CTC e MO $(0,91)$. Outras correlações importantes identificadas entre as variáveis físicas e químicas são: Ds e porosidade $(-0,98)$; $\mathrm{V}$ e $\mathrm{pH}(0,82)$; $\mathrm{Al}$ e V $(-0,83)$, Al e pH $(-0,93)$ e H + Al e CTC $(0,97)$.

Os atributos físicos e químicos selecionados para a observação da evolução do substrato apresentaram maior ou menor grau de mudanças principalmente na camada superficial e em razão do conjunto de atividades da revegetação. A profundidades maiores que $60 \mathrm{~cm}$, os resultados não apresentam modificações no tempo, aspecto relevante para a definição de amostragem em estudos vindouros.

Da observação dos parâmetros CAP e altura das plantas constatou-se que o desenvolvimento das espécies é muito variado e os dosséis não são contínuos. Para uma análise comparativa, os resultados são apresentados por espécie arbórea na Tabela 3, para as 15 espécies mais frequentes em cada área de estudo. Na mata nativa não foram encontradas espécies comuns com as áreas revegetadas. A vegetação da área A1 (14 anos) apresenta indivíduos de maior porte e cobertura. $\mathrm{Na}$ área $\mathrm{A} 2$

Tabela 3. Resultados médios de CAP $(\mathrm{cm})$ e altura $(\mathrm{m})$ das espécies mais frequentes nas áreas de estudo.

Table 3. Circumference at breast height $(\mathrm{cm})$ and height $(\mathrm{m})$ averages of the most frequent species in the observed areas.

\begin{tabular}{|c|c|c|c|c|c|c|c|c|c|c|}
\hline \multirow{3}{*}{ Espécie arbórea } & \multicolumn{10}{|c|}{ Áreas } \\
\hline & \multicolumn{2}{|c|}{ A1 - 14 anos } & \multicolumn{2}{|c|}{ A2 - 11 anos } & \multicolumn{2}{|c|}{ A3 - 8 anos } & \multicolumn{2}{|c|}{ A4 - 6 anos } & \multicolumn{2}{|c|}{ A5 - mata } \\
\hline & CAP & Altura & CAP & Altura & CAP & Altura & CAP & Altura & CAP & Altura \\
\hline Peltophorum dubium & 20,8 & 5,6 & 17,2 & 3,9 & 22,3 & 6,1 & 16,5 & 4,7 & - & - \\
\hline Schinus terebentifolium & 20,8 & 5,1 & 11,9 & 2,9 & 17,3 & 5,0 & 13,7 & 3,9 & - & - \\
\hline Acacia poliphilla & 39,4 & 7,8 & 9,8 & 2,8 & 34,6 & 8,0 & 17,7 & 4,2 & - & - \\
\hline Lafoensia pacari & 17,0 & 5,3 & 12,4 & 3,1 & 13,0 & 4,6 & 8,3 & 3,0 & - & - \\
\hline Psidium guajaba & 11,6 & 4,4 & 14,6 & 3,7 & 11,1 & 4,0 & 9,3 & 3,0 & - & - \\
\hline Inga edulis & 15,7 & 4,6 & 10,3 & 3,2 & 21,0 & 5,8 & 19,5 & 4,9 & - & - \\
\hline Enterolobium contortisiliquum & - & - & 34,4 & 4,0 & 39,0 & 6,5 & 33,0 & 5,3 & - & - \\
\hline Pseudobombax manguba & 17,9 & 6,5 & 11,9 & 3,2 & 20,0 & 4,1 & 9,0 & 2,9 & - & - \\
\hline Jacaranda micrantha & 14,4 & 4,9 & 5,0 & 2,0 & 10,0 & 5,5 & 18,0 & 3,8 & - & - \\
\hline Croton floribundus & 26,9 & 6,2 & 15,9 & 3,9 & 15,0 & 5,0 & - & - & - & - \\
\hline Hymenaea stigonocarpa & 14,5 & 6,0 & 6,3 & 1,9 & 10,5 & 4,1 & - & - & - & - \\
\hline Inga uruguensis & 18,7 & 5,7 & 14,5 & 3,9 & 28,7 & 8,3 & 7,4 & 2,7 & - & - \\
\hline Pterogyne nitens & 27,5 & 7,8 & - & - & 9,83 & 4,3 & 8,0 & 2,6 & - & - \\
\hline Luehea paniculata & 8,0 & 3,5 & 7,7 & 2,6 & 15,0 & 3,6 & 10,7 & 2,7 & - & - \\
\hline Tabebuia cassineoides & 18,0 & 4,5 & 6,0 & 1,5 & 9,0 & 2,3 & 9,3 & 2,5 & - & - \\
\hline Nectandra cuspidata & - & - & - & - & - & - & - & - & 12,4 & 5,4 \\
\hline Copaifera langsdorffii & - & - & - & - & 11,0 & 4,6 & - & - & 15,9 & 5,3 \\
\hline Mollinedia schottiana & - & - & - & - & 7,0 & 2,8 & - & - & 7,7 & 4,2 \\
\hline Tapirira guianensis & - & - & - & - & - & - & 13,0 & 4 & 32,1 & 7,6 \\
\hline Xylopia aromática & - & - & - & - & - & - & 14,0 & 4,1 & 23,3 & 6,6 \\
\hline Rapanea umbellata & - & - & - & - & - & - & - & - & 14,6 & 5,7 \\
\hline
\end{tabular}

- espécies não presentes na área. 
(11 anos), o comportamento das espécies reflete uma quebra de linearidade no desenvolvimento da vegetação, pois tanto para CAP como para altura os valores médios observados na maioria das espécies são menores que na área A3 (8 anos) e até que os observados na área A4 (6 anos), com revegetação mais recente. Esperava-se que quanto mais antiga a revegetação, melhor seria o comportamento dessas variáveis. Mas os valores obtidos devem refletir a compactação severa identificada na área $\mathrm{A} 2$, que estaria impedindo que a vegetação tenha um desenvolvimento progressivo condizente com a idade. Isso favorece o crescimento do capim braquiária, pois o desenvolvimento precário das espécies arbóreas não fornece sombreamento apropriado, que impede o crescimento do capim. Quanto à diversidade, a composição florística da mata nativa é pouco similar à das revegetações, como mostra a Tabela 3. Para fins de ilustração, a Tabela 3 também mostra as seis espécies mais frequentes observadas na mata nativa.

A Tabela 4 mostra o índice de diversidade $\mathrm{H}^{\prime}$ e o número de espécies arbóreas encontradas em cada área. Embora a mata nativa apresente o maior H', o valor obtido de 2,79 é baixo se comparado aos valores entre 3,30 e 3,56 encontrados por Angelo \& Angelini (2007) para áreas de Cerradão similares. $\mathrm{O}$ valor encontrado na mata reflete certo grau de degradação, resultado do antigo uso da área para extração de madeira para lenha. Nas revegetações, destaca-se a área A3 (8 anos) onde, mesmo com a riqueza de espécies próxima à da mata nativa, a existência em grande número de exemplares de uma única espécie influencia o valor de H’. É o caso da quantidade elevada de indivíduos de Inga sp. nessa área. Na área A1 (14 anos), que apresenta H’ mais próximo ao da mata nativa, observa-se sub-bosque ralo e incipiente, com regeneração de espécies do entorno e das espécies plantadas. Na área A2 (11 anos), o número de espécies é igual ao da área A1 (14 anos), o que indica que as condições negativas do substrato não têm resultado na diminuição da população arbórea, embora tenha influenciado seu menor desenvolvimento e tamanho, conforme Tabela 3.

Espécies arbóreas de regeneração natural identificadas na área A1 (14 anos) foram Gochnata polyforma, Cassia ferruginea, Copaifera langsdorfii e Ocotea pulchella; na área A2 (11 anos), Gochnata polyforma e Baccaris dracunculifolia; na área A3 (8 anos), Copaifera langdorsfii, Solanum mauritanum e Xylopia aromática; e na área A4, Guazuma ulmifolia e Vernonia polyanthes. Essas espécies de crescimento espontâneo são resistentes às condições físicas e químicas da bacia de rejeitos, observação que coincide com as de Corrêa \& Melo (2007), que defendem a necessidade de se identificarem espécies lenhosas espontâneas para plantio em áreas mineradas. A regeneração natural já estava acontecendo, porém a presença de braquiária era o filtro biótico que dificultava que o processo de diversificação da comunidade vegetal fosse mais acelerado e dinâmico.

\subsection{Obtenção dos indicadores de desempenho da revegetação}

No monitoramento de áreas mineradas onde o solo tenha sido fortemente degradado, a mensuração periódica dos parâmetros do substrato é estratégia essencial na verificação da recuperação da área, fornecendo informação importante para a gestão do processo de recuperação. Daí decorre a necessidade de se identificarem os parâmetros que possam servir de indicadores do estado do substrato. A Tabela 5 apresenta os resultados da análise de covariâncias multivariada realizada, mostrando que as variáveis significativas do substrato que contribuem para o comportamento das duas variáveis resposta (altura e CAP), para as condições da bacia de rejeito estudada, são a densidade de solo (Ds), os teores de MO e de fósforo e o $\mathrm{pH}$. Esses são, portanto, os parâmetros que comportaram-se efetivamente como indicadores da qualidade do substrato e, consequentemente, como indicadores do desempenho da revegetação. Isso não significa que as outras variáveis sejam dispensáveis, mas,

Tabela 4. Índice de diversidade de Shannon-Wiever ( $\left.\mathrm{H}^{\prime}\right)$ e número de espécies (NE).

Table 4. Shannon-Wiever diversity index ( $\left.\mathrm{H}^{\prime}\right)$ and number of species (NE).

\begin{tabular}{ccccccc}
\multicolumn{8}{c}{ Áreas } \\
\hline H' & A1 (14 anos) & A2 (11 anos) & A3 (8 anos) & A4 (6 anos) & A5 (mata nativa) \\
NE & 2,52 & 2,4 & 2,42 & 2,28 & 2,79 \\
\hline
\end{tabular}


Tabela 5. Variáveis significativas no teste multivariado para o modelo de análise de covariâncias multivariado. Table 5. Significant variables in multivariate test for the model of multivariate analysis of covariance.

\begin{tabular}{|c|c|c|c|c|}
\hline \multicolumn{2}{|c|}{ Efeito Testes } & Valor & $\mathbf{F}$ & p-valor \\
\hline \multirow{4}{*}{ Densidade } & Pillai's Trace & 0,014 & 5,428 & 0,005 \\
\hline & Wilks' Lambda & 0,986 & 5,428 & 0,005 \\
\hline & Hotelling's Trace & 0,014 & 5,428 & 0,005 \\
\hline & Roy's Largest Root & 0,014 & 5,428 & 0,005 \\
\hline \multirow{4}{*}{$\mathrm{pH}$} & Pillai's Trace & 0,021 & 8,235 & 0,000 \\
\hline & Wilks' Lambda & 0,979 & 8,235 & 0,000 \\
\hline & Hotelling's Trace & 0,022 & 8,235 & 0,000 \\
\hline & Roy's Largest Root & 0,022 & 8,235 & 0,000 \\
\hline \multirow{4}{*}{ Matéria orgânica } & Pillai's Trace & 0,008 & 2,972 & 0,052 \\
\hline & Wilks' Lambda & 0,992 & 2,972 & 0,052 \\
\hline & Hotelling's Trace & 0,008 & 2,972 & 0,052 \\
\hline & Roy's Largest Root & 0,008 & 2,972 & 0,052 \\
\hline \multirow{4}{*}{ Fósforo } & Pillai's Trace & 0,022 & 8,558 & 0,000 \\
\hline & Wilks' Lambda & 0,978 & 8,558 & 0,000 \\
\hline & Hotelling's Trace & 0,023 & 8,558 & 0,000 \\
\hline & Roy's Largest Root & 0,023 & 8,558 & 0,000 \\
\hline \multirow{4}{*}{ Alumínio } & Pillai's Trace & 0,043 & 16,924 & 0,000 \\
\hline & Wilks' Lambda & 0,957 & 16,924 & 0,000 \\
\hline & Hotelling's Trace & 0,045 & 16,924 & 0,000 \\
\hline & Roy's Largest Root & 0,045 & 16,924 & 0,000 \\
\hline \multirow{4}{*}{ СТC } & Pillai's Trace & 0,013 & 4,955 & 0,007 \\
\hline & Wilks' Lambda & 0,987 & 4,955 & 0,007 \\
\hline & Hotelling's Trace & 0,013 & 4,955 & 0,007 \\
\hline & Roy's Largest Root & 0,013 & 4,955 & 0,007 \\
\hline
\end{tabular}

CTC: capacidade de troca catiônica.

numa combinação entre influência sobre a vegetação e aspecto prático do monitoramento, as variáveis mencionadas mostraram-se mais representativas para esse exercício. Como exemplo, o teor de $\mathrm{Al}^{+3}$, mesmo sendo considerado significativo (Tabela 5), foi desconsiderado para a escolha pois, com o manejo de $\mathrm{pH}$, os altos teores de $\mathrm{Al}$ irão automaticamente diminuir. Também é o caso da CTC, influenciada pelas mudanças no teor de MO.

Com os resultados obtidos para as variáveis selecionadas e buscando orientar uma avaliação de desempenho da revegetação, foi elaborada a Tabela 6 utilizando-se os valores de referência, os níveis críticos e as taxas de reposição. Os valores de referência representam os valores esperados para os quais a revegetação deverá ter um desenvolvimento satisfatório. Os níveis críticos são estabelecidos com base na observação da evolução das variáveis e nos valores mínimos das médias encontradas nas áreas, conforme mostrado na Tabela 2, e indicam os valores mínimos necessários para a condução da revegetação.
Para a variável teor de matéria orgânica, o nível crítico é 14 g. $\mathrm{dm}^{-3}$ e o valor de referência na mata nativa é $25 \mathrm{~g} . \mathrm{dm}^{-3}$, sendo que nas áreas revegetadas esse valor foi superado. Para a densidade do solo, o nível crítico resulta $1,55 \mathrm{Mg} \cdot \mathrm{m}^{-3}$ para a revegetação da área A2 (11 anos), sendo o único valor que tem uma evolução negativa em relação à área A6 (sem revegetação), com Ds similar ao da mata nativa de 1,14 Mg.m ${ }^{-3}$ (valor de referência), o que significa que a compactação, gerada com as atividades operacionais, não diminui com o desenvolvimento da vegetação, sendo importante considerar novas estratégias no manejo para enfrentar tal situação.

No caso do $\mathrm{pH}$, tanto o solo da mata como os substratos das áreas revegetadas são ácidos. $\mathrm{O}$ manejo para correção deve ser observado, mais especificamente, na implantação, para melhorar a disponibilidade de $\mathrm{P}$ e dos demais nutrientes adicionados pela adubação e, assim, permitir o bom desenvolvimento das mudas. Posteriormente, o fornecimento de nutrientes deveria ser ativado pelo processo de ciclagem de nutrientes, 
Tabela 6. Indicadores de desempenho da revegetação na Mineração Descalvado.

Table 6. Revegetation performance indicators of Descalvado mine.

\begin{tabular}{lccccc} 
Indicador de & $\begin{array}{c}\text { Situação mais } \\
\text { desempenho } \\
\text { desfavorável (sem } \\
\text { revegetação) }\end{array}$ & $\begin{array}{c}\text { Valor } \\
\text { recomendado p/ } \\
\text { implantação* }\end{array}$ & $\begin{array}{c}\text { Nível crítico na } \\
\text { revegetação }\end{array}$ & $\begin{array}{c}\text { Valor de } \\
\text { referência }\end{array}$ & $\begin{array}{c}\text { Taxa de } \\
\text { reposição na } \\
\text { melhor } \\
\text { situação (\%) }\end{array}$ \\
\hline $\mathrm{MO}\left(\mathrm{g} \cdot \mathrm{dm}^{-3}\right)$ & 7 & 10 & 14 & 25 & 400 \\
\hline $\mathrm{Ds}\left(\mathrm{Mg} \cdot \mathrm{m}^{-3}\right)$ & 1,14 & 1,20 & 1,55 & 1,14 & - \\
$\mathrm{P}\left(\mathrm{mmolc} \cdot \mathrm{dm}^{-3}\right)$ & 1 & 10 & 8 & 5 & 1.200 \\
\hline $\mathrm{pH}$ & 4,0 & $5,6-6,2$ & 3,8 & 3,6 & - \\
\hline
\end{tabular}

${ }^{*}$ Obtido em referências bibliográficas; MO: teor de matéria orgânica; Ds: densidade de solo; P: teor de fósforo.

não sendo necessário realizar mais correções, pois os valores de referência são baixos. Torna-se necessário considerar os valores para implantação de mudas apontadas pela bibliografia, de modo a acelerar seu processo de desenvolvimento nos primeiros anos. As taxas de reposição indicam o quanto a variável aumentou na melhor situação das revegetações em relação à situação mais desfavorável, observando-se que os valores de $\mathrm{MO}$ e $\mathrm{P}$ nas áreas revegetadas superam os valores de referência, refletindo uma melhoria nutricional associada ao manejo dessas áreas.

\section{CONCLUSÕES}

Mediante a aplicação do método investigativo proposto verificou-se que os atributos físicos e químicos selecionados podem ser usados como indicadores das mudanças que acontecem no substrato, refletindo sua influência no crescimento das plantas. Nas condições das bacias de rejeitos estudadas, determinou-se que a densidade do solo, o teor de matéria orgânica, o teor de fósforo e o $\mathrm{pH}$ são os parâmetros que refletem mais convenientemente o desenvolvimento da vegetação arbórea implantada, concluindo-se que são os indicadores mais apropriados para avaliação das características do substrato. Ações de aperfeiçoamento do manejo devem focar-se na melhoria desses indicadores, especialmente a densidade de solo (Ds), que apresenta restrições severas ao desenvolvimento de plantas.

O método proposto demonstra-se satisfatório como instrumento de monitoramento, é de aplicação relativamente fácil, ao não requerer ensaios de alta complexidade ou custos elevados. Trata-se de uma ferramenta que pode ser adotada pelas empresas de mineração em rotinas de monitoramento de áreas degradadas em vias de recuperação, aplicando-se tanto a bacias de rejeitos (o caso estudado) como, potencialmente, a outras áreas degradadas pela mineração, como cavas e pilhas de estéril.

\section{STATUS DA SUBMISSÃO}

Recebido: 6 jan., 2014

Aceito: 10 out., 2014

\section{AUTOR(ES) PARA CORRESPONDÊNCIA}

\section{Luis Enrique Sánchez}

Departamento de Engenharia de Minas e de Petróleo, Universidade de São Paulo - USP, CEP 05508-900, São Paulo, SP, Brasil e-mail: 1sanchez@usp.br

\section{REFERENNCIAS}

Ab'Sáber AN. Ecossistemas do Brasil. São Paulo: Metalivros; 2009.

Almeida ROPO, Sánchez LE. Revegetação de áreas de mineração: critérios de monitoramento e avaliação de desempenho. Revista Árvore 2005; 29(1): 47-54. http:// dx.doi.org/10.1590/S0100-67622005000100006.

Angelo PG, Angelini R. Similaridade e diversidade florística entre fitofisionomias do cerrado. Revista Saúde e Ambiente 2007; 8(2): 28-36.

Bento MAB. Avaliação da qualidade dos substratos minerados em cinco cascalheiras revegetadas no Distrito Federal[dissertação]. Brasília: Departamento de Engenharia Florestal, Faculdade de Tecnologia, Universidade de Brasília; 2009.

Brady NC, Weil RR. The nature and properties of soils. 13 . ed. Upper Saddle River: Prentice Hall; 2007.

Coelho RMP. Fundamentos em ecologia. Porto Alegre: Artes Médicas Sul; 2000. 
Corrêa RS, Bento MAB. Qualidade do substrato minerado de uma área de empréstimo revegetada no Distrito Federal. Revista Brasileira de Ciência do Solo 2010; 34(4): 1435-1443. http://dx.doi.org/10.1590/S0100-06832010000400039.

Corrêa RS, Melo B Fo. Levantamento florístico do estrato lenhoso das áreas mineradas no Distrito Federal. Revista Árvore 2007; 31(6): 1099-1108. http://dx.doi.org/10.1590/ S0100-67622007000600015.

Costa S, Zocche JJ. Fertilidade de solos construídos em áreas de mineração de carvão na região sul de Santa Catarina. Revista Árvore 2009; 33(4): 665-674. http:// dx.doi.org/10.1590/S0100-67622009000400009

Knapik P, Maranho LT. Avaliação da revegetação em área de mineração, região de inundação do rio Iguaçu, Araucária, PR. Revista Brasileira de Biociências 2007; 5(supl. 1): 507-509.

Machado PLOA. Compactação de solo e crescimento de plantas - como identificar, evitar e remediar. Rio de Janeiro: Embrapa Solos; 2003. Embrapa Solos, Documentos n. 56.

Neri AC, Sánchez LE. A procedure to evaluate environmental rehabilitation in limestone quarries. Journal of Environmental Management 2010; 91(11): 2225-2237. http://dx.doi. org/10.1016/j.jenvman.2010.06.005. PMid:20630648

Reis L. Monitoramento da recuperação ambiental de áreas de mineração de bauxita na Floresta Nacional de Saracá
Porto Trombetas (PA) [tese]. Rio de Janeiro: Instituto de Agronomia, Universidade Federal de Rio de Janeiro; 2006. Sánchez LE. Planejamento e gestão do processo de recuperação de áreas degradadas. In: Filippini-Alba JM, organizador. Recuperação de áreas degradadas: a visão dos especialistas brasileiros. 2. ed. Pelotas: Embrapa Clima Temperado; 2010 .

Sentelhas PC, Pereira, AR, Marin FR, Angelocci LR, Alfonsi $\mathrm{RR}$, Caramori $\mathrm{PH}$, et al. Balanços hídricos climatológicos do Brasil - 500 balanços hídricos de localidades brasileiras. Piracicaba: ESALQ; 1999.

Silva LCR, Corrêa RS. Evolução da qualidade do substrato de uma área minerada no cerrado revegetada com Stylosanthes spp. Revista Brasileira de Engenharia Agrícola e Ambiental 2010; 14(8): 835-841. http://dx.doi. org/10.1590/S1415-43662010000800007.

Tanaka NI, Chu BC, Yassunaga Y. Relatório de Análise Estatística sobre o Projeto: Indicadores de Qualidade do Solo para Monitoramento de Áreas Revegetadas - Estudo Dirigido à Mineração de Areia. São Paulo: Instituto de Matemática e Estatística da USP; 2009.

Troeh F, Thompson LM. Solos e fertilidade do solo. 6. ed. São Paulo: Andrei Editora; 2007. 